\title{
Pengaruh Sarana Prasarana dan Lingkungan Kerja terhadap Kinerja Guru
}

\author{
Anggi Angrainy ${ }^{\bowtie 1}$, Happy Fitria ${ }^{2}$, Yessi Fitiani ${ }^{3}$ \\ (1) Sekolah Menengah Pertama Negeri 6 Unggul Sekayu
}

$(2,3)$ Universitas PGRI Palembang

$\square$ Corresponding author

[anggiangrainy588@gmail.com]

\begin{abstract}
Abstrak
Tujuan penelitian ini yaitu untuk: 1) mengetahui dan mendeskripsikan pengaruh sarana prasarana terhadap kinerja guru kinerja guru; 2) mengetahui dan mendeskripsikan pengaruh lingkungan kerja terhadap kinerja guru; 3) mengetahui dan mendeskripsikan pengaruh sarana prasarana dan lingkungan kerja terhadap kinerja guru. Jenis penelitian ini adalah penelitian kuantitatif. Hasil penelitian disimpulkan bahwa: 1) sarana prasarana berpengaruh terhadap kinerja guru; 2) lingkungan kerja berpengaruh terhadap kinerja guru; 3) sarana prasarana dan lingkungan kerja berpengaruh bersama-sama terhadap kinerja guru.
\end{abstract}

Kata Kunci: Sarana Prasarana; Lingkungan Kerja, Kinerja Guru

\section{Abstract}

Abstract: The objectives of this study were to: 1) identify and describe the effect of infrastructure on teacher performance; 2) knowing and describing the influence of the work environment on teacher performance; 3) identify and describe the effect of infrastructure and work environment on teacher performance. This type of research is quantitative research. The results of the study concluded that: 1) infrastructure has an effect on teacher performance; 2 ) the work environment affects teacher performance; 3 ) infrastructure and work environment jointly influence teacher performance.

\section{Keyword: Infrastructure, Work Environment; Teacher Performance.}

\section{PENDAHULUAN}

Pendidikan merupakan bagian paling penting untuk mencerdaskan dan memajukan kehidupan suatu bangsa. Sesuai amanat Pancasila dan Undang-Undang Dasar 1945, keinginan bangsa Indonesia untuk dapat maju dan berkembang menjadi suatu bangsa yang disegani dan berperan besar dimata dunia, hal ini dapat terwujud bila dengan peningkatan kualitas manusia Indonesia. Suatu bangsa maju jika pendidikannya maju dan berkualitas, dan sebaliknya bangsa menjadi mundur jika kualitas pendidikannya. Pada dasarnya, terdapat berbagai faktor yang mempengaruhi keberhasilan pendidikan, antara lain: guru, siswa, sarana dan prasarana, lingkungan pendidikan, kurikulum. Dari beberapa faktor tersebut, guru dalam kegiatan proses pembelajaran di sekolah menempati kedudukan yang sangat penting dan tanpa mengabaikan faktor penunjang yang lain, guru sebagai subjek pendidikan sangat menentukan keberhasilan pendidikan itu sendiri (Widoyoko dan Rinawat, 2012).

Education is the most important indicator of a country's progress (Asvio et al, 2019). Education is a conscious effort to build quality human resources to compete (Tobari et al, 2018). Quality human resources are more important than the wealth of natural resources, because the wealth of natural resources cannot guarantee the welfare and success of a nation (Asvio et al, 2019).

Proses pendidikan merupakan kejadian berubahnya sesuatu menjadi sesuatu yang lain. Sesuatu yang berpengaruh terhadap berlangsungnya proses yang di sebut input, sedangkan sesuatu dari hasil proses disebut output. Dalam pendidikan berskala mikro yaitu tingkatan sekolah, proses yang dimaksud meliputi proses pengambilan keputusan, pengelola kelembagaan, pengelolaan program, proses belajar mengajar serta proses monitoring dan evaluasi, dengan catatan bahwa proses belajar mengajar memiliki tingkat kepentingan tertinggi dibandingkan dengan proses-proses yang lain. Proses dikatakan bermutu tinggi apabila pengorganisasian dan penyerasian seta pemaduam input sekolah yaitu guru, peserta didik, uang, peralatan, dan perlengkapan menunjang lainnya tersedia. Penyelarasan dilakukan secara harmonis dan terpadu sehingga mampu menciptakan situasi pembelajaran yang menyenangkan, mendorong motivasi dan minat belajar dan mampu memperdayakan peserta didik. Dengan kata lain peserta didik tidak sekedar menguasai pengetahuan yang diajarkan oleh guru, tetapi pengetahuan tersebut juga telah menjadi muatan nurani peserta didik, 
dihayati, diamalkan dalam kehidupan sehari-hari, dan yang penting lagi peserta didik mampu belajar secara mandiri mengajar yang efektif.

Iklim sekolah baik fisik dan non fisik yang kondusif merupakan prasyarat bagi terselenggaranya proses belajar lingkungan sekolah yang aman dan tertib, optimism dan harapan/ekspektasi yang tinggi dari warga sekolah, kesehatan sekolah, dan kegiatan-kegiatan yang terpusat pada peserta didik adalah contoh iklim sekolah yang dapat menumbuhkan semangat belajar siswa, sehingga yang diperlukan adalah upaya yang lebih intensif.

Selain faktor-faktor diatas faktor ekonomi guru juga berpengaruh terhadap kinerja guru, dalam dunia pendidikan yang sangat berkembang pesat. Kemajuan teknologi juga menjagi faktor pendukung yang sangat besar. Guru di tuntut untuk menguasai teknologi sesuai dengan perkembangan teknologi pada saat sekarang ini. Tidak semua guru mempunyai peralatan teknologi penunjang dalam erah 4.0, dimana semua kemajuan dunia pendidikan bisa kita lihat di dunia digital. Pada pembelajarn kurikulum 2013, guru di tuntut untuk mengembangkan keahliannya dalam bidang teknologi dimana setiap pelajaran diharuskan belajar dengan perkembangan pendidikan negara-negara maju di dunia.

Pentingnya pendidikan menuntut pemerintah untuk fokus dalam pengembangan sumber daya manusia yang berilmu, kreatif, inovatif dan mandiri. Hal tersebut tercantum dalam undang-undang No.20 Tahun 2003 Bab II Pasal 3 yang berbunyi bahwa "Pendidikan Nasional berfungsi mengembangkan kemampuan dan membentuk watak serta peradaban bangsa, yang bertujuan untuk mengembangkan potensi dan kemampuan peserta didik supaya menjadi manusia yang beriman dan bertaqwa kepada Tuhan Yang Maha Esa, berahlak mulia, sehat, berilmu, kreatif, inovatif, mandiri bisa berkerja, mandiri dan bertanggung jawab".

Ada 4 fungsi dasar dalam tujuan pendidikan yaitu: 1) pengembangan individu yang meliputi aspekaspek hidup pribadi, etis, estetis, emosional dan fikis; 2) pengembangan cara berfikir dan teknik penyelidikan yang berkenaan dengan kecedasan yang terlatih; 3) pemindahan warisan budaya, menyangkut nilai-nilai sivik dan moral bangsa; 4) pemenuhan kebutuhan sosial yang vital yang menyumbang kepada kesejahteraan ekonomi, sosial, politik, dan lapangan kerja (Rohiat, 2010).

Di dalam sebuah lembaga pendidikan kita mengenal beberapa komponen antara lain pendidik, peserta didik, tenaga kependidikan, serta komite sekolah. Selain itu ada juga faktor pendukung lainya, antara lain faktor eksternal dan faktor internal. Dalam kegiatan pelaksanaannya ada dua komponen utama yang tidak dapat terpisahkan yaitu pendidik atau guru dan peserta didik. Dalam pelasanaan belajar mengajar ada komponen penunjang yang wajib ada sehingga kegiatan pembelajaran terpenuhi yaitu kinerja guru dalam menyajikan materi pembelajaran. Menguasai bahan dan menggunakan sumber belajar untuk membangkitkan proses belajar mengajar aktif melalui pengembangan keterampilan proses, mengenali perbedaan kemampuan peserta didik serta memberikan bimbingan yang diperlukan sehingga nilai proses dan hasil belajar memberikan umpan balik (Wardani, 2014).

Pembelajaran adalah wahana yang dirancang oleh pendidik secara sadar untuk mencapai tujuan pendidikan. Pembelajaran terwujudkan dalam interaksi belajar-mengajar yang dinamis dan diarahkan kepada pencapaian tujuan, yaitu perubahan perilaku dan pribadi peserta didik yang optimal. Perubahan yang terjadi pada peserta didik itu ditampilkan dalam karakter, sebagai perilaku yang dilandasi nilai-nilai kehidupan yang sangat luhur.

Hampir semua orang dikenai pendidikan dan melaksanakan pendidikan. Sebab pendidikan tidak pernah terpisahkan dengan kehidupan manusia. Anak-anak menerima pendidikan dari orang tuanya dan manakala anak-anak ini sudah dewasa dan berkeluarga, mereka juga akan mendidik anak-anaknya. Begitu pula di sekolah dan perguruan tinggi, para siswa dan mahasiswa dididik oleh guru dan dosen. Pendidikan adalah khas milik dan alat manusia, tidak ada makhluk lain yang membutuhkan pendidikan (Pidarta, 2013).

Yamin dan Maisah (2010) mengemukakan kinerja merupakan suatu konstruksi multidimensi yang mencakup banyak faktor yang mempengaruhinya. Factor tersebut terdiri dari; 1) faktor personal atau individual, meliputi unsur pengetahuan, keterampilan, kemampuan, percaya diri, motivasi, dan komitmen yang dimiliki oleh tiap individu guru; 2) faktor kepemimpinan, meliputi aspek kualitas mengajar dan tem leader dalam member dorongan, semangat, arahan, dukungan kerja pada guru; 3) faktor tim, meliputi kualitas dukungan dan semangat yang diberikan rekan dalam satu tim, kepercayaan terhadap sesama anggota tim, kekompakan, dan keeratan anggota tim; 4) faktor sistem, meliputi system kerja, fasilitas kerja yang diberikan oleh pimpinan sekolah, proses organisasi sekolah dan kultur kerja dalam organisasi sekolah; dan 5) faktor kontekstual, meliputi tekanan dan perubahan lingkungan eksternal individu dan kelompok terhadap kinerja organisasi sekolah. Sarana yang memadai, sekolah tidak hanya melahirkan calon ilmuwan, tetapi juga calon ulama, olahragawan, dan seniman karena anak diberi kesempatan seluas-luasnya untuk menjadi diri mereka sendiri. Guru membaca dan mengarahkan serta melatih siswa sesuai bakatnya masing-masing. Dengan sarana yang memadai dan guru yang kompeten, pendidikan tersebut akan berjalan baik dan lancar (Musfah, 2015).

Sarana prasarana yang dimiliki sekolah merupakan faktor pendukung terlasananya program sekolah, khususnya kegiatan pembelajaran yang dilakukan oleh guru. Terkait dalam penelitian ini sarana dan prasarana 
merupakan faktor yang sangat penting dalam peningkatan kinerja guru. Sarana dan prasarana yang lengkap dan baik merupakan penunjang kegiatan belajar mengaja disekolah agar tercapai hasil yang optimal.

Berdasarkan hasil wawancara guru dibeberapa SMP Negeri Negeri di Kecamatan Sekayu, melalui wakil bagian saran prasarana tanggal 18 Nopember 2019 didapatkan informasi bahwa bebrapa sekolah tersebut memiliki sarana prasarana yang kurang menunjang dalam proses pembelajaran. Beberapa saran yang belum tersediah berkaitan dengan sarana olahraga, belum tersediahnya laboratorium bahasa, peralatan dan perlengkapan di laboratorium komputer maupun laboratorium IPA sebagian sudah kurang memadai untuk digunakan dalam kegiatan belajar mengajar sehingga proses belajar tidak maksimal.

Kinerja guru merupakan keberhasilan guru dalam menjalankan tugas dan tanggung jawab sebagai tenaga professional berdasarkan standar kinerja. Agar supaya dapat menjalankan tugas dan tanggung jawab tersebut perlunya sarana dan prasarana sebagai fasilitas pendukung baik langsung maupun tidak langsung dalam pembelajaran di sekolah. Selain itu lingkungan kerja mampu membentuk prilaku yang berhubungan dengan kondisi kondisi kerja sehingga dapat mempengaruhi pribadinya dalam menjalankan tugas dan pekerjaannya.

Berkaitan dengan peningkatan kinerja guru selain faktor pemanfaatan sarana prasarana dan kesejahteraan. Faktor kepribadian seorang guru dapat mempengaruhi kinerja. Guru memiliki tugas sebagai pendidik, dan pembimbing, untuk menjadi pendidik seorang guru harus memiliki kepribadian yang baik. Guru memang seorang pendidik sekaligus sebagai pembimbing sebab dalam pekerjaanya tidak hanya mengajar, namun melatih beberapa keterampilan dan sikap mental anak didik (Sardiman, 2012). Beberapa faktor yang mempengaruhi kinerja guru antara lain kepribadian dan dedikasi, pengembangan profesi, kemampuan mengajar berdasarkan sarana dan prasarana yang mendukung, antar hubungan dan komunikasi, hubungan dengan masyarakat, kedisiplinan, kesejahteraan dan iklim kerja (Rachmawati, 2013).

Dari hasil observasi awal yang peneliti lakukan di SMP di Kecamatan Sekayu, fenomena yang terjadi antara lain: 1) kurangnya perawatan sarana prasarana berupa peralatan teknologi informasi dan alat-alat praktik, hal ini ditandai dengan banyaknya peralatan praktik yang rusak sehingga kurang maksimalnya hasil belajar; 2) adanya kesenjangan guru senior dan guru junior sehingga munculnya iklim yang kurang kondusif yang berakibat dengan kinerja guru; dan 3) kurangnya pemahaman guru terhadap perkembangan teknologi dan informasi di dunia pendidikan, hal ini ditandai dengan hasil supervisi guru yang nilai penggunaan teknologi informasinya tidak pernah meningkat dari waktu ke waktu. Berdasarkan masalah yang ada di latar belakang maka peneliti tertarik untuk meneliti dengan judul "Pengaruh Sarana Prasarana dan Lingkungan Kerja terhadap Kinerja Guru SMP Negeri di Kecamatan Sekayu".

\section{METODE PENELITIAN}

Menurut Sugiyono (2016) metode penelitian pada dasarnya merupakan cara ilmiah untuk mendapatkan data dengan tujuan dan kegunaan tertentu. Berdasarkan hal tersebut terdapat empat kata kunci yang perlu diperhatikan yaitu cara ilmiah, data, tujuan dan kegunaan. Jenis penelitian ini adalah penelitian kuantitatif. Menurut Musfiqon (2012) penelitian kualitatif adalah penelitian yang difokuskan pada kajian fenomena objektif untuk dikaji secara kuantitatif. Pengumpulan data pada penelitian ini dilakukan secara kuantitatif.

Penelitian ini menggunakan metode korelasi parsial, yang digunakan untuk analisis atau pengujian hipotesis apabila peneliti bermaksud mengetahui pengaruh atau hubungan variabel independen dengan dependen, dimana salah satu variabel independennya dikendalikan (Sugiyono, 2016). Sedangkan Noor (2011) menyatakan penelitian kuantitatif merupakan metode untuk menguji teori-teori tertentu dengan cara meneliti hubungan variable. Variabel-variabel ini biasanya diukur dengan menggunakan instrumen penelitian sehingga data yang terdiri dari angka-angka dapat dianalisis berdasarkan prosedur statistik. Adapun dalam penelitian ini sampel yang di gunakan yaitu 3 SMP Negeri di kecamatan Sekayu dengan jumlah sampel = jumlah populasi $\times 30 \%=243 \times 30 \%=73$ guru.

\section{HASIL DAN PEMBAHASAN}

\section{Pengujian Hipotesis Parsial Variabel Sarana Prasarana (X1) terhadap Kinerja Guru (Y)}

Berdasarkan hasil analisis yang telah diuraikan di atas diperoleh hasil bahwa variabel (X1) kepemimpinan kepala sekolah berpengaruh secara signifikan terhadap variabel $(\mathrm{Y})$ Kinerja guru di SMP Negeri Prabumulih. Berdasarkan uji t, dimana nilai thitung > dari t tabel. Dengan demikian didapatkan bahwa Ho ditolak dan Ha diterima, sehingga didapatkan bahwa kepemimpinan kepala sekolah mempunyai pengaruh yang signifikan terhadap kinerja guru. Dari hasil analisa diketahui bahwa responden sebanyak 99 dihasilkan nilai korelasi sebesar 0,98. Dari data diatas dapat diambil kesimpulan bahwa ada korelasi signifikan antara variabel kepemimpinan kepala sekolah (X1) terhadap variabel Kinerja Guru (Y). Dari hasil koefisien diterminasi maka dapat diketahui nilai r2. Nilai ini mengandung arti bahwa pengaruh kepemimpinan kepala sekolah (X1) terhadap Kinerja Guru (Y) adalah sebesar 97\% sedangkan sisanya Kinerja Guru dipengaruhi oleh variabel lain yang tidak diteliti di dalam penelitian ini. Dengan kata lain, kinerja guru dapat ditingkatkan 
dengan peran kepemimpinan kepala sekolah. Semakin baik peran kepemimpinan kepala sekolah, maka semakin baik pula kinerja guru.

Hal ini didukung oleh penelitian terdahulu menurut Syaroni (2007) kepemimpinan kepala sekolah berpengaruh signifikan terhadap kinerja guru. Ini berarti bahwa kepemimpinan kepala sekolah dapat mempengaruhi tinggi rendahnya kinerja seorang guru. Penting bagi seorang kepala sekolah untuk mengetahui bagaimana tipe-tipe dan pola kepemimpinan untuk meningkatkan kinerja guru.

Peningkatan kinerja guru, berdasarkan hasil penelitian, dapat dilakukan dengan meningkatkan peran seorang pemimpin dalam mengarahkan dan memotivasi, membobilisasi, bahkan membagi tugas guru sesuai tupoksi agar menghasilkan guru-guru dengan kinerja yang berkualitas, dan proses pembelajaran akan berjalan baik juga.

Tabel 1. Hasil Koefisien Analisis Regresi Linear Sederhana secara Parsial Variabel Sarana Prasarana $\left(\mathrm{X}_{1}\right)$ terhadap Kinerja Guru $(\mathrm{Y})$

\begin{tabular}{|c|c|c|c|c|c|c|}
\hline \multicolumn{7}{|c|}{ Coefficients $^{\mathrm{a}}$} \\
\hline & \multirow[t]{2}{*}{ Model } & \multicolumn{2}{|c|}{$\begin{array}{l}\text { Unstandardized } \\
\text { Coefficients }\end{array}$} & $\begin{array}{c}\text { Standardized } \\
\text { Coefficients }\end{array}$ & \multirow[t]{2}{*}{$\mathrm{T}$} & \multirow[t]{2}{*}{ Sig. } \\
\hline & & $B$ & $\begin{array}{l}\text { Std. } \\
\text { Error }\end{array}$ & Beta & & \\
\hline \multirow[t]{2}{*}{1} & (Constant) & 90.936 & 9.022 & & 10.079 & .000 \\
\hline & $X_{1}$ & .193 & .076 & .290 & 2.551 & .013 \\
\hline
\end{tabular}

Tabel 2. Hasil Analisis Koefisien Determinasi Variabel Sarana Prasarana $\left(\mathrm{X}_{1}\right)$ terhadap Kinerja Guru (Y)

\begin{tabular}{|l|l|l|l|l|}
\hline \multicolumn{5}{|c|}{ Model Summary } \\
\hline Model & $\mathrm{R}$ & $\mathrm{R}$ Square & \multicolumn{1}{|c|}{$\begin{array}{c}\text { Adjusted R } \\
\text { Square }\end{array}$} & $\begin{array}{c}\text { Std. Error of the } \\
\text { Estimate }\end{array}$ \\
\hline 1 & $.290^{\mathrm{a}}$ & .084 & .071 & 8.674 \\
\hline \multicolumn{4}{|l}{ a. Predictors: (Constant), $\mathbf{X}_{1}$} \\
\hline
\end{tabular}

\section{Pengujian Hipotesis Parsial Variabel Lingkungan Kerja (X2) terhadap Variabel Kinerja Guru $(\mathrm{Y})$}

Dari hasil penelitian menunjukan bahwa sarana prasarana berpengaruh positif dan signifikan terhadap kinerja guru. Hasil ini didukung oleh hipotesis yang diajukan dimana sarana prasarana berpengaruh signifikan terhadap kinerja guru. Menurut hasil perhitungan berdasarkan persamaan regresi linier sederhana yang berpedoman pada tabel nilai koefisien pada $\mathrm{X}_{1}$ dapat dijelaskan bahwa jika nilai Lingkungan kerja $\left(\mathrm{X}_{2}\right)$ meningkat unit skor, maka kinerja guru akan meningkat sebesar 0.366 pada nilai koefisien $X_{2}$. satu unit skor dengan menentukan nilai lingkungan kerja $\left(X_{2}\right)$ adalah konstan. Mengenai ada tidaknya pengaruh yang signifikan antara lingkungan kerja $\left(\mathrm{X}_{2}\right)$ terhadap kinerja guru $(\mathrm{Y})$ dapat dilihat pada besarnya nilai thitung yang terdapat pada tabel. Nilai thitung lingkungan kerja 2, 551 dengan signifikan 0,000 $(\rho<0,05)$ dengan tabel sebesar 1,993 maka thitung $\geq$ tabel, maka menolak $\mathrm{H}_{0}$ dan menolak $\mathrm{H}_{\mathrm{a}}$ atau dapat dikatakan hal ini menunjukkan ada pengaruh yang signifikan antara variabel sarana prasarana $\left(X_{1}\right)$ terhadap kinerja guru $(Y)$ sebesar $24,7 \%$. (Nilai R², Tabel 4).

Hasil penelitian ini membuktikan bahwa semakin baik lingkungan kerja maka akan semakin baik juga kinerja guru dalam proses pembelajaran disekolah. Demikian sebaliknya jika lingkungan kerja kurang baik maka kinerja guru akan menurun.

Tabel 3. Hasil Koefisien Regresi Linear Sederhana secara Parsial Varaiabel Lingkungan Kerja $\left(\mathrm{X}_{2}\right)$ terhadap Kinerja Guru $(Y)$

\begin{tabular}{|c|c|c|c|c|c|c|}
\hline \multicolumn{7}{|c|}{ Coefficients ${ }^{a}$} \\
\hline \multirow{2}{*}{\multicolumn{2}{|c|}{ Model }} & \multicolumn{2}{|c|}{$\begin{array}{l}\text { Unstandardized } \\
\text { Coefficients }\end{array}$} & $\begin{array}{c}\text { Standardized } \\
\text { Coefficients }\end{array}$ & \multirow[t]{2}{*}{$\mathrm{T}$} & \multirow[t]{2}{*}{ Sig. } \\
\hline & & B & Std. Error & Beta & & \\
\hline \multirow[t]{2}{*}{1} & (Constant) & 61.149 & 10.947 & & 5.586 & .000 \\
\hline & $X_{2}$ & .366 & .076 & .497 & 4.827 & .000 \\
\hline
\end{tabular}


Tabel 4. Hasil Analisis Koefisien Determinasi Variabel Lingkungan kerja $\left(\mathrm{X}_{2)}\right.$ terhadap Kinerja Guru $(\mathrm{Y})$

\begin{tabular}{|l|c|c|c|c|}
\hline \multicolumn{5}{|c|}{ Model Summary } \\
\hline Model & $\mathrm{R}$ & $\mathrm{R}$ Square & $\begin{array}{c}\text { Adjusted R } \\
\text { Square }\end{array}$ & $\begin{array}{c}\text { Std. Error of } \\
\text { the Estimate }\end{array}$ \\
\hline 1 & $.497^{\mathrm{a}}$ & .247 & .237 & 7.864 \\
\hline a. Predictors: (Constant), $\mathrm{X}_{2}$ \\
\hline
\end{tabular}

\section{Pengujian Hipotesis Simultan Variabel X1 dan X2 ke Y}

Dari hasil penelitian memperlihatkan pengaruh sarana prasarana dan lingkungan kerja berpengaruh yang signifikan terhadap kinerja guru. Hasil ini mendukung hipotesis yang diajukan dimana sarana prasarana dan lingkungan kerja berpengaruh signifikan terhadap kinerja guru. Menurut hasil penghitungan tabel. Nilai koefisien pada variabel $\mathrm{X}_{1}$ dan $\mathrm{X}_{2}$ dapat dijelaskan bahwa sarana prasarana $\left(\mathrm{X}_{1}\right)$ dan lingkungan kerja $\left(\mathrm{X}_{2}\right)$ meningkat unit skor maka kinerja guru $(Y)$ akan meningkat sebesar 0,084 ditambah sebesar 0,247 pada nilai koefisien $\mathrm{X}_{2}$.

Satu unit skor pada nilai sarana prasarana $\left(X_{1}\right)$ dan nilai lingkungan kerja $\left(X_{2}\right)$ adalah konstan. Dengan mengambil taraf sifnifikan signifikan 0,000 $(\rho<0,05)$ dengan $t_{\text {tabel }}$ sebesar 1,993 maka thitung $\geq t_{\text {tabel, }}$ maka menolak $\mathrm{H}_{0}$ dan $\mathrm{H}_{\mathrm{a}}$ diterima, hal ini dapat dilihat dari uji-f diketahui $\mathrm{f}_{\text {hitung }}=11,514$ dan $\mathrm{f}_{\text {tabel }}=3,128$ artinya dapat disimpulkan bahwa ada pengaruh secara simultan antara sarana prasarana dan lingkungan kerja terhadap kinerja guru serta menunjukan hubungan positif terhadap kinerja guru dengan konstribusi $24,8 \%$ (Nilai $\mathrm{R}^{2}$, tabel 7). Hal ini menunjukan bahwa variabel sarana prasarana dan lingkungan kerja mempengaruhi kinerja guru secara bersama-sama menyumbang sebesar $24,8 \%$ dan $75,2 \%$ faktor-faktor lainnya yang tidak ada hubungan dengan penelitian ini.

Teacher's performance can be defined as the extent to which a teacher works to the fullest in accordance with his abilities in an effort to achieve institutional goals (Rohma et al, 2020). Kinerja guru sangat penting untuk dikaji karena banyak faktor yang mempengaruhi kinerja guru selain variabel yang peneliti teliti, diantaranya: 1) manajemen berbasis sekolah; 2) profesionalisme guru; 3) kompetensi pedagogik; 4) dan lain sebagainya (Rohma et al, 2020; Murkatik et al, 2020).

Tabel 5. Hasil Analisis ANOVA Regresi Linear Berganda Variabel Sarana Prasarana $\left(X_{1}\right)$ dan Lingkungan Kerja $\left(\mathrm{X}_{2)}\right.$ secara Simultan terhadap Kinerja Guru (Y)

\begin{tabular}{|c|c|c|c|c|c|c|}
\hline \multicolumn{7}{|c|}{ ANOVAa $^{a}$} \\
\hline & Model & $\begin{array}{l}\text { Sum of } \\
\text { Squares }\end{array}$ & Df & Mean Square & $\mathrm{F}$ & Sig. \\
\hline \multirow[t]{3}{*}{1} & Regression & 1443.447 & 2 & 721.723 & 11.514 & $.000^{\mathrm{b}}$ \\
\hline & Residual & 4387.869 & 70 & 62.684 & & \\
\hline & Total & 5831.315 & 72 & & & \\
\hline \multicolumn{7}{|c|}{ a. Dependent Variable: $Y$} \\
\hline
\end{tabular}

Tabel 6. Hasil Analisis Koefisien Regresi Linear Berganda Variabel Sarana Prasarana $\left(\mathrm{X}_{1}\right)$ dan Lingkungan $\operatorname{Kerja}\left(\mathrm{X}_{2}\right)$ secara Simultan terhadap Kinerja Guru $(\mathrm{Y})$

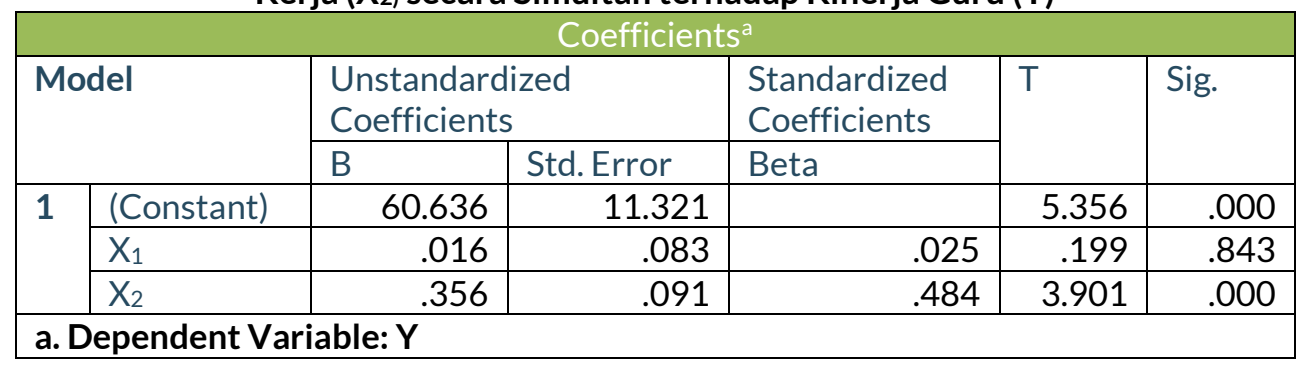

Tabel 7. Hasil Analisis Koefisien Determinasi Variabel $X_{1}$ dan $X_{2}$ secara Simultan tehadap $Y$

\begin{tabular}{|l|l|l|l|l|}
\hline \multicolumn{5}{|c|}{ Model Summary } \\
\hline Model & $\mathrm{R}$ & $\mathrm{R}$ Square & $\begin{array}{l}\text { Adjusted R } \\
\text { Square }\end{array}$ & $\begin{array}{l}\text { Std. Error of } \\
\text { the Estimate }\end{array}$ \\
\hline 1 & $.498^{\mathrm{a}}$ & .248 & .226 & 7.917 \\
\hline a. Predictors: (Constant), $\mathbf{X}_{2}, \mathbf{X}_{1}$ \\
\hline
\end{tabular}




\section{SIMPULAN}

Sarana prasarana berpengaruh terhadap kinerja guru SMP Negeri di Kecamatan Sekayu yang dapat dilihat dari thitung $(2,551)>$ ttabel $(1,993)$. Besarnya pengaruh variabel $X 1$ terhadap nilai $Y$ adalah sesuai dengan persamaan garis $Y=90,936+0,290 X 1$. Sedangkan besarnya konstribusi persamaan garis $X 2$ terhadap $\mathrm{Y}$ dapat dilihat dari derajat koefisien determinasinya sebesar 8,4 persen. Lingkungan kerja berpengaruh terhadap kinerja guru SMP Negeri di Kecamatan Sekayu yang dapat dilihat dari thitung $(4,827)>$ ttabel $(1,993)$. Besarnya pengaruh variabel $X 1$ terhadap nilai $Y$ adalah sesuai dengan persamaan garis $Y=24,255+$ $0,336 X 1$. Sedangkan besarnya konstribusi persamaan garis $X 2$ terhadap $Y$ dapat dilihat dari derajat koefisien determinasinya sebesar 24,7 persen. Sarana prasarana dan lingkungan kerja berpengaruh bersama-sama terhadap kinerja guru SMP Negeri di Kecamatan Sekayu yang dapat dilihat dari fhitung $=11,514>$ Ftabel $=$ 3,128 dan besarnya pengaruh variabel $X 1$ dan $X 2$ terhadap nilai $Y$ adalah sesuai dengan persamaan garis $Y=$ $60,635+0,160 \times 1+0,356 X 2$. Sedangkan besarnya konstribusi persamaan garis $X 1$ terhadap $Y$ dapat dilihat dari derajat koefisien determinasinya sebesar 24,8 persen.

\section{UCAPAN TERIMA KASIH}

Ucapan terima kasih diberikan kepada Kepala SMP Negeri 6 Unggul Sekayu dan Rektor Universitas PGRI Palembang yang telah membantu dalam penyelesaian jurnal ini. Kemudian terima kasih juga kepada teman-teman dan semua pihak yang telah membantu penulisan dan penerbitan jurnal ini.

\section{DAFTAR PUSTAKA}

Asvio, N., Yamin, M., \& Risnita. (2019). Influence of Leadership Style, Emotional Intelligence and Job Satisfaction toward Organizational Commitment (Survey at SMA Muhammadiyah South Sumatera). International Journal of Scientific \& Technology Research 8 (8).

Murkatik, K., Harapan, E., \& Wardiah, D. (2020). The Influence of Professional and Pedagogic Competence on Teacher's Performance. Journal of Social Work and Science Education, 1(1), 58-69. Retrieved from https://ejournal.karinosseff.org/index.php/jswse/article/view/10

Musfah, J. (2015). Manajemen Pendidikan Teori, Kebijakan, dan Praktik. Jakarta: Prenadamedia Group.

Musfiqon. (2012). Pengembangan Media Belajar dan Sumber Belajar. Jakarta: Prestasi Pustakakarya.

Noor, J. (2011). Metode Penelitian. Jakarta: Prenada Media Group.

Pidarta, M. (2013). Landasan Kependidikan Stimulus Ilmu Pendidikan Bercorak Indonesia. Jakarta: Rineka Cipta.

Rachmawati, T. (2013). Penilaian Kinerja Profesi Guru dan Angka Kreditnya. Yogyakarta: Gava Media.

Rohiat. (2010). Manajemen Sekolah. Bandung: Refika Aditama.

Rohma, S., Harapan, E., \& Wardiah, D. (2020). The Influence of School-Based Management and Teacher's Professionalism toward Teacher's Performance. Journal of Social Work and Science Education, 1(1), 13-23. Retrieved from https://ejournal.karinosseff.org/index.php/jswse/article/view/6

Sardiman, A. M. (2012). Interaksi dan Motivasi Belajar Mengajar. Jakarta: PT Raja Grafindo Persada.

Sugiyono. (2016). Metode Penelitian Kuantitatif, Kualitatif dan R\&D. Bandung: Alfabeta.

Tobari., Kristiawan, M. \& Asvio, N. (2018). The Strategy of Headmaster on Upgrading Educational Quality in Asean Economic Community (AEC) Era. International Journal of Scientific \& Technology Research 7 (4).

Wardani, L. K. (2014). Pengaruh Kepemimpinan, Motivasi Kerja, dan Komitmen Organisasi terhadap Kepuasan Kerja dalam Meningkatkan Kinerja Guru SMP NegeriKota Tegal. Tesis. Semarang: Program Pascasarjana Magister Manajemen Universitas Dian Nuswantoro Semarang.

Widoyoko, S. E. P., \& Rinawat, A. (2012). Pengaruh Kinerja Guru terhadap Motivasi Belajar Siswa. Cakrawala Pendidikan Jurnal IImiah Pendidikan 2 (2012).

Yamin, M., \& Maisah. (2010). Standarisasi Kinerja Guru. Jakarta: GP Press 